\title{
Swelling pressure of a sodium bentonite in solutions of different suction
}

\author{
Shin Sato ${ }^{1}$, Shuichi Yamamoto ${ }^{1}$ and Tomoyoshi Nishimura ${ }^{2}$ \\ ${ }^{1}$ Nuclear waste technology department, Obayashi Corporation, Japan \\ ${ }^{2}$ Department of Civil Engineering, Ashikaga University, Japan
}

\begin{abstract}
In this study, the swelling pressure of unsaturated, compacted bentonite-sand mixture was measured, which the all samples had experiment in dying-wetting history in suction changing. This test program used Kunigel V1 as sodium type. Constant volume swelling test was conducted out that swelling pressure was measured using a developed apparatus. A pressure sensor was mounted in the swelling test apparatus. Previously, the all samples deformed due to suction change (i.e. drying-wetting process in suction). Two types were prepared before applying suction that were initial unsaturated condition and saturated condition on same initial dry density. Swelling pressure and adsorbed water amount was monitored in the test, which lasted for one month.
\end{abstract}

\section{Introduction}

Swelling test is the relevant test related to hydraulic behavior used for bentonite but its measurement is significant time consuming and testing performance is rather expensive. In essentially, high expansive bentonite barrier has a low hydraulic conductivity that prevents the seepage of water through the barrier with self-sealing. Swelling pressure in bentonite-sand mixture increases approximately with dry density. In generally, two types of bentonite are investigated: sodium bentonite and calcium bentonite, respectively. The swelling pressure can be determined in the laboratory by almost three different methods: constant volume, swell-load and zero swell-load. Laboratory measurements have concentrated on only swelling pressure. Other hands, swelling pressure and permeability were studied in both radial and axial directions using a small-scale compacted disk for evaluating back-fill with different dry densities. For some dry densities, higher peak values were observed in the radial direction than in the axial direction.

In order to adequately understand the swelling pressure of the unsaturated, compacted bentonite-sand mixture, an experimental work for soil-water characteristic curve (SWCC) is necessary. Suction contributes in strength, deformation and flow characteristics in unsaturated soils, namely adsorption of water on the surface of the clay minerals. Soil suction is defined as the water potential in a soil-water system. Various evaluations of the SWCC in unsaturated soils have been demonstrated that suction is controlled some methods: pressure plate technique, pressure membrane technique and vapor pressure technique. Measured suction ranges depend on each method. The vapor equilibrium methods and osmotic technique have gained widespread acceptances as reliable methods for controlling vapor fluxes. The vapor equilibrium method allows to evaluate changes in soil-water characteristic curve. Moisture transport in bentonite under suction impact is a topic of great interest from two decade ago. Problems that hydration induced moisture movement in unsaturated, compacted bentonite is an important phenomenon corresponding to barrier structure. It is necessary to quantify the vapor fluxes in bentonite due to applied thermal gradients.

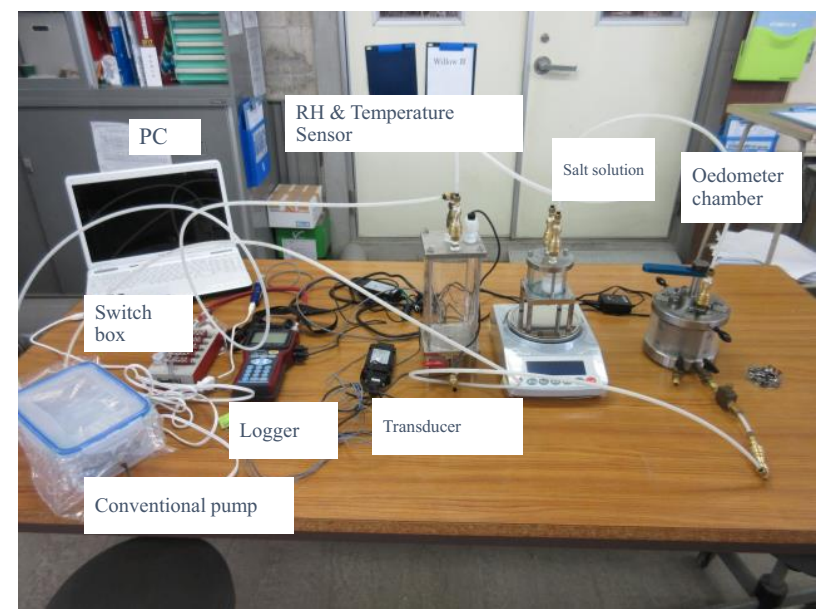

Photo 1. High suction control system used vapor pressure technique.

\footnotetext{
$\overline{2}$ Corresponding author: tomo@ashitech.ac.jp
} 


\section{Purpose of this study}

In this study, the swelling pressure of unsaturated, compacted bentonite-sand mixture was measured, which the all of samples had experiment in dying-wetting processes in suction changing. This test program used Kunigel V1 classified as sodium type. Constant volume swelling test was conducted out that swelling pressure was measured under remaining constant in specimen volume. A pressure sensor was mounted in the swelling test apparatus. Previously, the all of samples deformed due to suction change (i.e. drying-wetting process in suction). Two types were prepared before applying suction which were unsaturated condition and saturated condition on same initial dry density. Swelling pressure and adsorbed water amount were monitored during the test, which lasted for one month.

\section{Testing procedure}

\subsection{Soil materials and summary of specimens}

The testing program used two different soil materials that sodium bentonite and silica sand. Silica sand had uniformity grain size distribution, which was obtained by Test method for particle size distribution of soils (JIS A 1204: 2009). All of specimens had a diameter of $6.0 \mathrm{~cm}$ and $2.0 \mathrm{~cm}$ in size, and were compacted statically in a dry density of $1.600 \mathrm{~g} / \mathrm{cm}^{3}$ with water content of $17.0 \%$. The mixture ratio was $70 \%$ to $30 \%$. The silica sand occupied $30 \%$ to whole dry mass.

\subsection{Testing apparatus}

A vapor pressure technique using some salt solutions supported to interpret water retention capacity of bentonite accurately under various relative humidity conditions. This study conducted out applying of high suction to bentonite-sand mixture specimens using a $\mathrm{RH}$ circulation system as shown in Photo 1, which was composing two chambers, conventional pump, PC, RH \& Temperature sensor, logger and oedemeter chamber. The installed sensor referring white colour measured both RH and temperature. Among two chambers and conventional pump were connected flexible tube, and the system was completely closed (i.e. closure). Salt solution in chamber produced a defined $\mathrm{RH}$ that suction corresponding to identified $\mathrm{RH}$ was possible to offer specimen in oedemeter chamber. All specimens had the influence of suction such as hydration effort due to various salt solution.

\subsection{Testing programs}

Experimental works in this study conducted out according to three different testing programs, which were measuring of soil-water characteristic curve, deformation induced by hydration and swelling pressure subjected to high suction. Almost of all required suctions were over $2.8 \mathrm{MPa}$ as high suction ranges.
Water retention test was conducted out using vapor pressure test. Soil-water characteristic curve that two different specimens were prepared, and one was unsaturated specimen with dry density of $1.600 \mathrm{Mg} / \mathrm{m}^{3}$ and water content of $17.0 \%$, another one was saturated specimen with a dry density of $1.600 \mathrm{Mg} / \mathrm{m}^{3}$. Firstly, suction of $2.8 \mathrm{MPa}$ due to RH $98 \%$ used Potassium Sulphate was controlled to specimen, and it subsequently, increased up to $296 \mathrm{MPa}$ (i.e. RH $11 \%$ ) as drying process. After suction of $296 \mathrm{MPa}$ had an equilibrium with specimen, recover process as wetting process began till suction down to $2.8 \mathrm{MPa}$.

Then, vertical deformation and changing of soil moisture were measured under a constant vertical stress of $200 \mathrm{kPa}$ for unsaturated specimen with dry density of $1.600 \mathrm{Mg} / \mathrm{m}^{3}$ and water content of $17.0 \%$. Air flow with various high suctions were through the specimen at least one month. Deformation permitted by various suction had a decision changing of void ratio and degree of saturation for specimens.

In addition, swelling pressure was determined that specimens swelled due to absorbed water under constant volume (i.e. not permit changing vertical deformation) during test. The specimens used in SWCC test above mentioned had different physical properties associated to suction, volume, dry density and soil moisture. It found that various swelling pressures were indicated when end of swelling pressure test.

\section{Soil-water characteristic curve}

Soil-water characteristic curve is fundamental key parameter which can explain the water retention activity, conductivity and hydration mechanical associated with suction. It generally describes relationship between suction and parameters including soil moisture such as water content and degree of saturation. Simulation mathematical models contribute to prediction hydrationmechanical phenomena for unsaturated bentonite so that Fredlund and Xing (1994) [1], Leong and Rahardjo (1997) [2] and Pham et al. (2005) [3] and proposed a developed SWCC simulation model. They considered Bio-modal style with high suction ranges. Particularly, suggested SWCC models attempted to describe two point of inflection on SWCC. SWCCs were described for two different specimens such as unsaturated condition and saturated condition before conducting SWCC test as shown in Figs 1 (unsaturated condition) and 2 (saturated condition). All data sets consisted of drying process and wetting process, and it was easy to find out hysteresis of degree of saturation with suction increment and reduction. Beyond suction was up to $296 \mathrm{MPa}$, indicated degree of saturation on wetting process was lower than that obtained in drying process. 


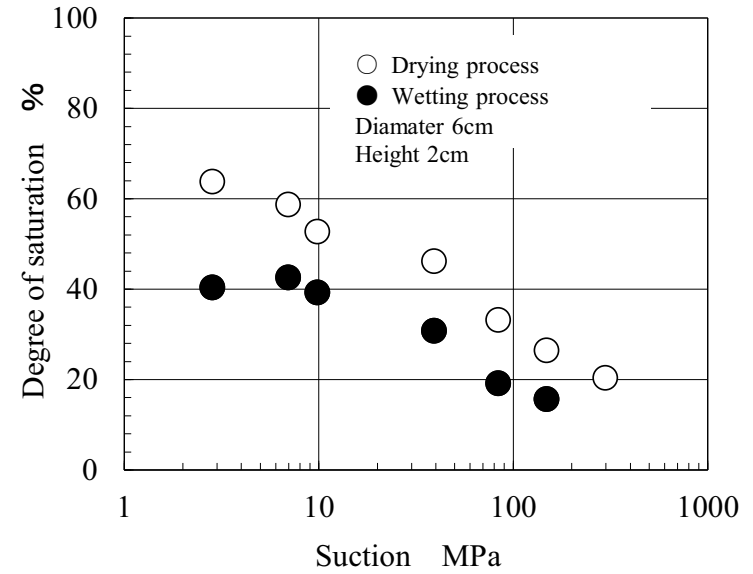

Figure 1. SWCC for unsaturated condition.

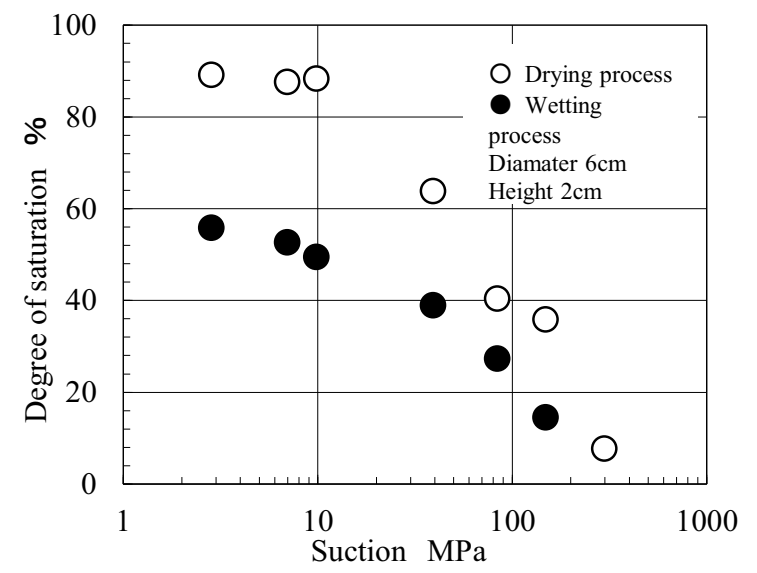

Figure 2. SWCC for saturated condition.

\section{Deformation due to suction changing}

It was accepted that suction reduction applied deformation such as completely failure. Lai et al. (2014) [4] measured volume change using unsaturated triaxial compression apparatus, which controlling matric suction cause deformation, and was possible to predict the slope stability. As similar unsaturated soil researches, Nazer and Tarantino (2016) [5] conducted out unsaturated soil creep test in order to investigate deformation behaviour associated with suction considering. The coverage literature is effectively to solve the hydration-mechanical properties for bentonite material. Measured void ratio according to decreasing of suction that indicated obviously large reduction with suction as shown in Fig. 3. It was recognized to be increment of soil moisture due to suction decreasing, evaluated degrees of saturation was indicated in Fig. 4. It is possible to evaluate that suction is a coverage factor regard to deformation.

\section{Swelling pressure under various suction}

Taking account of safety for radioactive waste barrier system, simulation mathematical models contribute to briefly to infer thermal-hydration-mechanical-chemical properties. Swelling pressure of significant stress state variable, as well as, defined LC curve using suction and pre-consolidation stress was further important factor. Reports mentioned above, Alonso et al (1990) [6] organized a fundamental theory for unsaturated constitutive framework that was possible to verify suction effect. Beyond constitutive model suggested by Alonso et al (1990) [6], a few studies have been developed the models based on modified Cam-clay model, and Cekerevac et al. (2003) [7] and Cekerevac et al. (2004) [8] indicated the influence of thermal effort to clay material.

This study performed swelling pressure test under constant volume (i.e. no permit changing of deformation). All of specimens were unsaturated condition which were used for determination of SWCC in Figs 1 and 2. Two swelling pressure behaviour were described as shown in Figs 5 and 6 that swelling pressure smoothly increased with time, and swelling pressure approached to equilibrium or stabilization when elapsed time was around 500 hours. Relationship between suction and evaluated swelling pressure are confined as shown in Fig. 6 . It is agreeability with previous works on literature that increment of suction caused the swelling pressure. Other hands, specified specimen, when specimens were saturated condition before SWCC test, produced swelling pressures obviously much larger than that of unsaturated specimen. Thus, physical parameters such as water content and dry density close influence on swelling pressure with except suction.

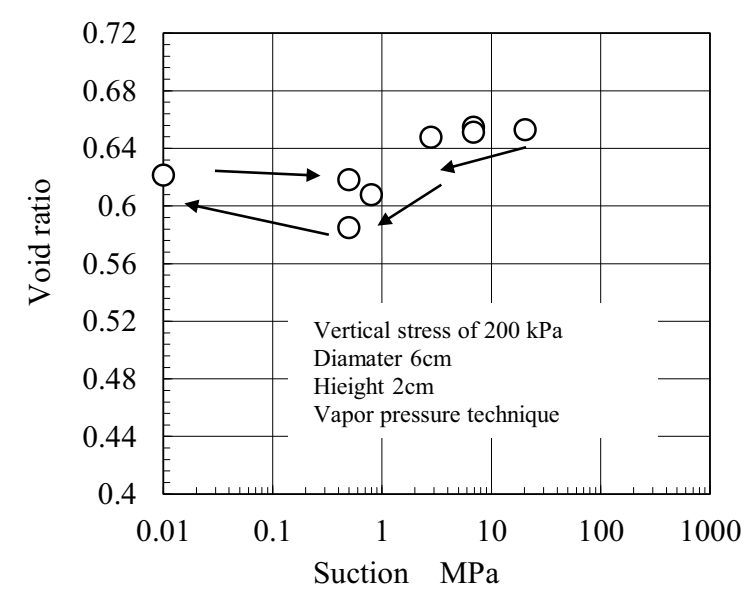

Figure 3. Changing of void ratio due to various suction.

\section{Conclusions}

This study conducted out hydration-mechanical tests such as SWCC test, deformation test and swelling pressure test to Sodium bentonite sand mixture. Soil-water characteristic curve described the difference either unsaturated condition and saturated condition before SWCC test. Deformation was measured under various suctions that it was exhibited to be effectively for suction influence. Swelling pressure at constant volume during absorption had further significant to physical factors through dry density, soil moisture and suction. 


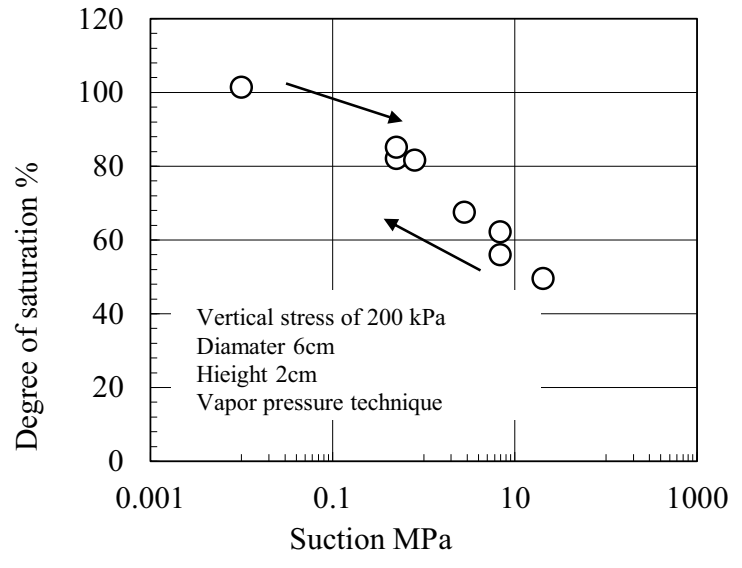

Figure 4. Changing of degree of saturation due to various suction.

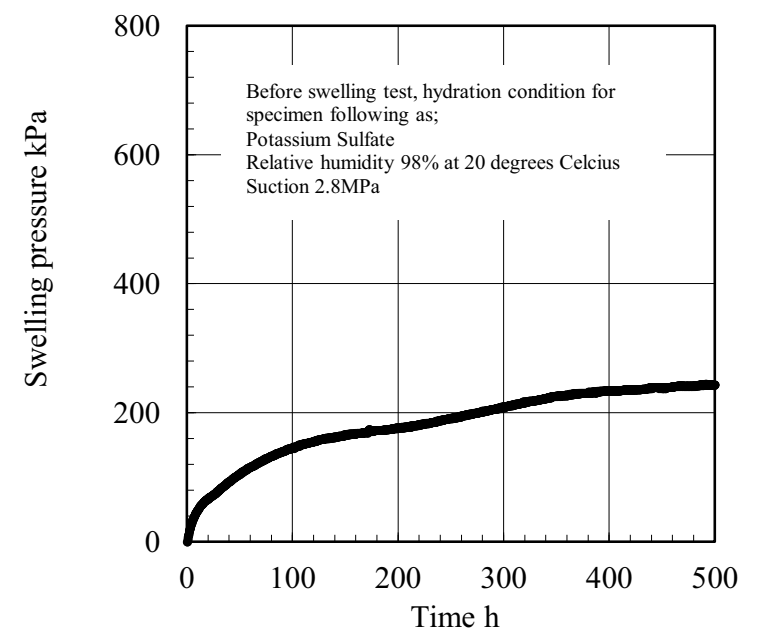

Figure 5. Increment of swelling pressure for specimen subjected to RH $98 \%$.

\section{References}

1. D.G. Fredlund, D.G. \& A. Xing. (1994). Equations for the soil-water characteristic curve, Canadian Geotechnical Journal, 31, 521-532.

2. E.C. Leong. \& H. Rahardjo. (1997). Review of soilwater characteristic curve equations, Journal of Geotechnical and Geoenvironmental Engineering, 123, 12, 1106-1117.

3. Q.H. Pham., D.G. Fredlund, \& S.L. Barbour. (2005): A study on the hysteresis models for soil-water characteristic curves, Can Geotech J 42(6), 15481568.

4. X.L. Lai., S.M. Ye.W. Wang, \& Y.J. Cui. (2014). Experimental investigation on the creep behavior of an unsaturated clay, Canadian Geotechnical Journal, 51(6), 621-628.

5. N.S.M. Nazer,\&A. Tarantino. (2016). Creep response in shear of clayey geo-materials under saturated and unsaturated conditions, Proceedings of the 3rd European Conference on Unsaturated Soils, EUNSAT 2016, DOI: 10.1051/e3sconf/20160914023.
6. E.E. Alonso, A. Gens, \& A. Josa. (1990). Constitutive model for partially saturated soils, Géotechnique, 40(3), 405-430.

7. C. Cekerevac, L. Laloui. \& L. Vulliet. (2003). A new temperature controlled triaxial apparatus, Proc. 3rd Int. Symp. Deformation Characteristics of Geomaterials, Lyon,133-137.

8. C. Cekerevac. \& L. Laloui. (2004). Experimental study of thermal effects on the mechanical behaviour of a clay. Int. J. Numer. Anal. Methods Geomech, 28, 3,209-228.

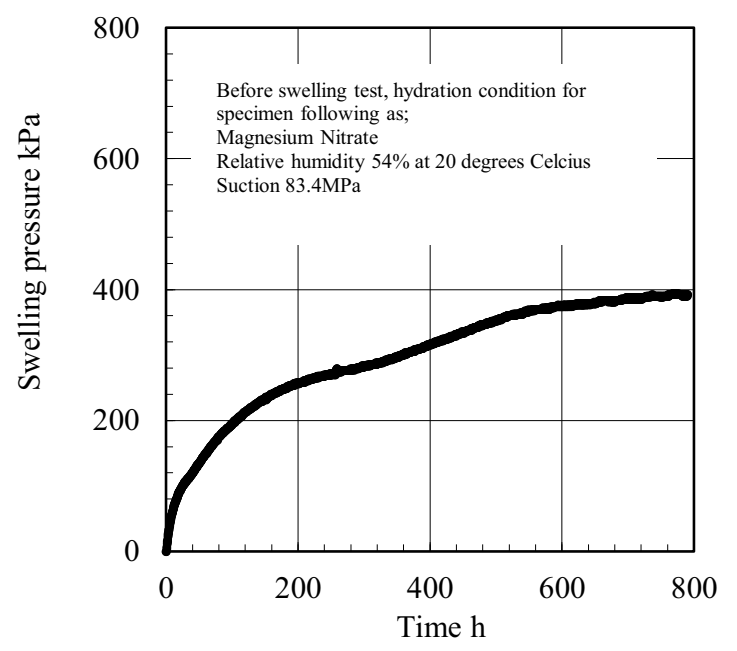

Figure 6. Increment of swelling pressure for specimen subjected to RH $54 \%$.

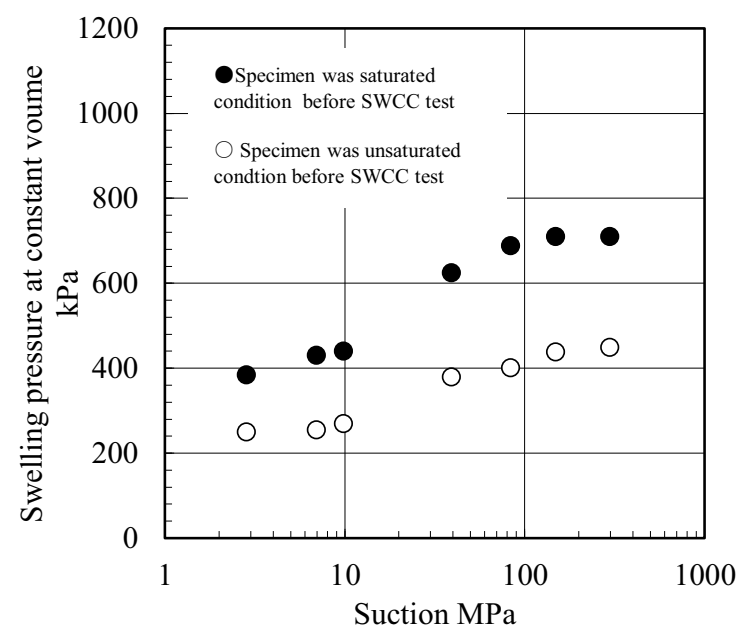

Figure 7. Evaluated swelling pressure for different suction past. 